\title{
Correction: NFATC2-rearranged sarcomas: clinicopathologic, molecular, and cytogenetic study of 7 cases with evidence of AGGRECAN as a novel diagnostic marker
}

Raul Perret $\mathbb{D}$ - Julien Escuriol • Valérie Velasco • Laetitia Mayeur • Isabelle Soubeyran • Christophe Delfour • Sébastien Aubert - Marc Polivka - Marie Karanian - Alexandra Meurgey • Sophie Le Guellec • Noelle Weingertner • Sylvia Hoeller · Jean-Michel Coindre · Frédérique Larousserie • Gaëlle Pierron • Franck Tirode (D) François Le Loarer (iD

Published online: 15 May 2020

(C) The Author(s), under exclusive licence to United States \& Canadian Academy of Pathology 2020

Correction to: Modern Pathology

https://doi.org/10.1038/s41379-020-0542-z

Since the publication of this paper, the authors noticed that there were some minor errors in the text to be corrected, as well as incorrect scale bars in Fig. 1. These errors have been corrected in the original manuscript and Fig. 1 has been replaced with accurate scale bars. The updated Fig. 1 and legend are below.
Fig. 1 Imaging and gross findings of NFATc2-

rearranged sarcomas. $\mathbf{a}, \mathbf{b}$ (case 4), magnetic resonance imaging with STIR (Short tau inversion recovery) showing a large tumor replacing the medullary cavity of the distal femur associated with a massive extra-osseous component.

Grossly, the tumor was a large fleshy mass with hemorrhagic areas and multilobular contours. c, d (case 7), radiograph of the surgical specimen showing an ill-defined lytic mass growing posteriorly into the soft tissues. Grossly, the tumor manifested as a large destructive fleshy mass breaking through the cortex and invading the surrounding tissues, note the marked periosteal reaction. Scale bars $5 \mathrm{~cm}$.
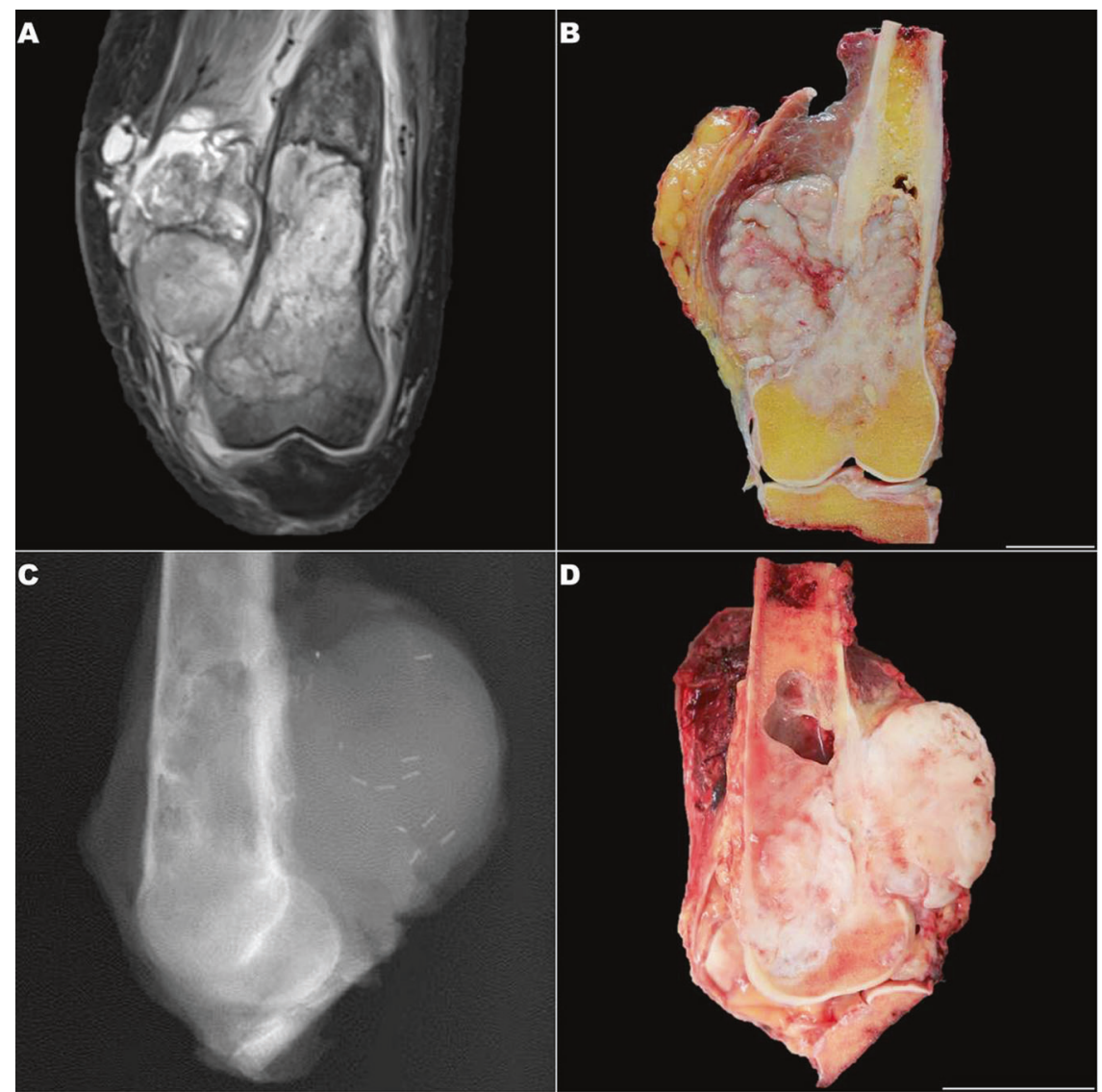